\title{
The unexpectedly low sensitivity of the nitrogen NMR shieldings of covalent azides to solvent effects
}

\author{
M. Witanowski ${ }^{1}$, W. Sicinska ${ }^{1}$ and G. A. Webb ${ }^{2 *}$, \\ 1. Institute of Organic Chemistry, Polish Academy of Science, 01-224 Warsaw, Poland \\ 2. Department of Chemistry, University of Surrey, Guildford, Surrey, UK
}

\begin{abstract}
The nitrogen shieldings of covalent azides are shown to be essentially independent of molecular interactions in solutions of a large variety of solvents. They present a rare case where substituent effects, exerted by an aryl or alkyl group attached to the azide, clearly surpass the range of solvent induced effects on the nitrogen shieldings. This occurs in spite of the large net change splitting in the electronic structure of the azide group and the presence of lone pair electrons on this group. The observed induced range of solvent effects does not exceed $2 \mathrm{ppm}$ in most cases which is similar to that previously observed for dinitrogen $\left(\mathrm{N}_{2}\right)$ and an azo bridged structure.
\end{abstract}

\section{Introduction}

Usually the nitrogen NMR shieldings (chemical shifts) of solute molecules are very sensitive to both specific and non-specific molecular interactions on solution [1]. Thus the nitrogen shieldings of solutes are potentially valuable sources of information about such interactions. The range of solvent induced nitrogen shielding changes of solute molecules can be as large as $50 \mathrm{ppm}$ [1]. The shielding sensitivity is particularly noticeable when solvent to solute hydrogen bonding takes place involving a lone pair of electrons on the nitrogen atom of interest.

Previously we have found only two exceptions to this observation, namely those in which the nitrogen shielding variations with solvent do not exceed $2 \mathrm{ppm}$. These include dinitrogen $\left(\mathrm{N}_{2}\right)$ [2] and the azobridge atoms in $\left.\left(\mathrm{CH}_{3}\right)_{3} \mathrm{C}-\mathrm{N}=\mathrm{N}-\mathrm{C}\left(\mathrm{CH}_{3}\right)_{3}\right)$ [3]. In the present study our aim is to investigate the effects of solvent on the nitrogen NMR shieldings of covalent azide groups. The general formulae of which are shown in Figure 1. The conventional resonance structures given reveal that a large positive charge is expected to be present at the central nitrogen atom $(\mathrm{N} \beta)$ and comparable negative changes on the other two nitrogen atoms $(\mathrm{N} \alpha)$ and $(\mathrm{N} \gamma)$ as represented in Figure 1. 


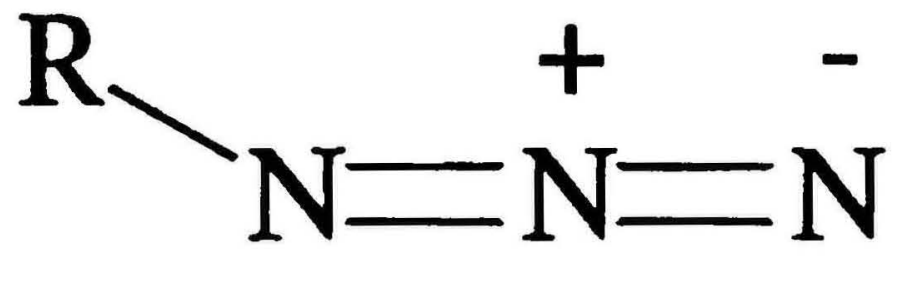

$\alpha \quad \beta \quad \gamma$

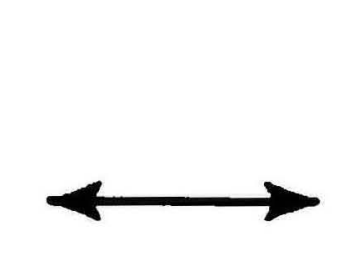

$\alpha$

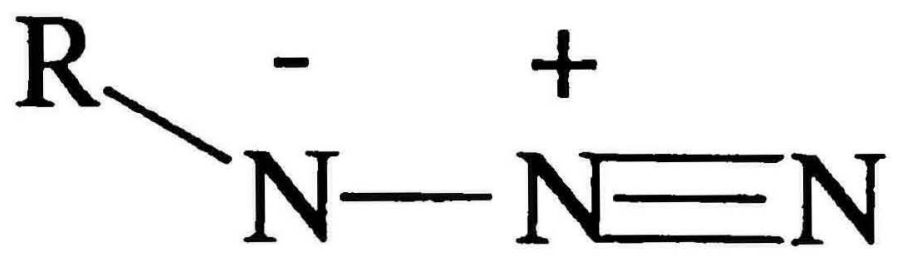

$\beta \quad \gamma$

Figure 1. Conventional resonance structures for covalent azides. These cannot be written without net charge splitting.

The conventional bonding structure of an azide group in terms of bonding and lone pair electrons is presented in Figure 2. This shows the presence of two lone pairs of electrons on $\mathrm{N} \alpha$ and $\mathrm{N} \gamma$. Hence we may anticipate an appreciable sensitivity of these nitrogen atoms to solute-solvent specific and non-specific interactions due to the presence of the lone pair electrons and the charge splitting shown.

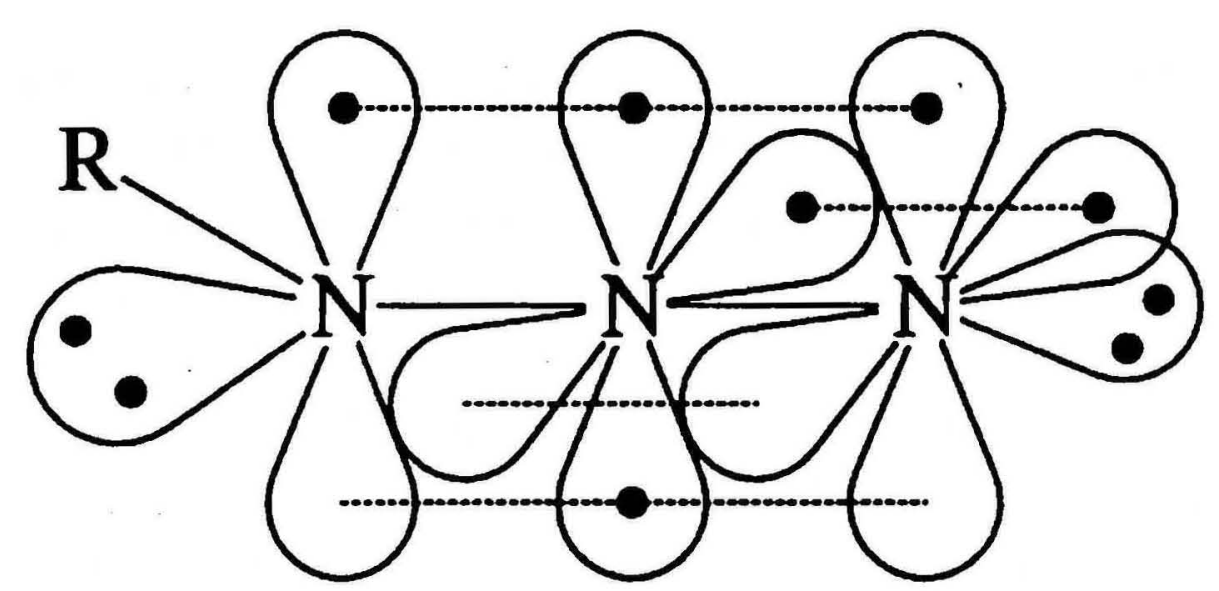

Figure 2. A schematic representation of the bonding system of a covalent azide, representing the $\pi$ electron system and the presence of lone pair electrons.

Ethyl azide, $\mathrm{R}=\mathrm{CH}_{3} \mathrm{CH}_{2}$ in Figure 1; and phenyl azide, $\mathrm{R}=$ Phenyl in Figure 1, are chosen as model compounds in the present study. The former of these represents alkyl azides where no conjugation of the $\pi$ electron system of the azide group can occur with the substituent $\mathrm{R}$. In phenyl azide some conjugation is expected between the $\pi$ electrons of the phenyl ring and the $\pi$ of the azide group. We also have studied three other covalent azides to investigate the influence of the group $R$ on the shieldings of the azide nitrogen atoms, where $R$ $=\mathrm{n}$-butyl, cyclohexyl and benzyl. Thus we may compare the relative influences of substituents and solvent effects on the shieldings of the azide nitrogen atoms.

\section{Results and discussion}

The results of high precision ${ }^{14} \mathrm{~N} N \mathrm{~N}$ shieldings, the details of which are given in the experimental section, for ethyl and phenyl azide are presented in Tables 1 and 2 respectively together with the ${ }^{14} \mathrm{~N}$ half-height widths of the corresponding resonance signals. The data reported are corrected for bulk susceptibility effects and are referenced to neat nitromethane as standard [1]. The sign convention chosen to report the nitrogen shieldings is that in which a positive sign denotes an increase in the shielding with respect to the reference, as used previously [1-3]. Thus the figures given represent difference in shielding of the nitrogen nuclei in the azides and that in nitromethane as reference. 
Table 1

The results of ${ }^{14} \mathrm{~N}$ NMR measurements taken on ethyl azide in a variety of solvents of which the concentration is $0.2 \mathrm{M}$.

\begin{tabular}{ccccccc}
\hline Solvent & \multicolumn{3}{c}{ Nitrogen shielding (ppm) } & \multicolumn{3}{c}{${ }^{14} \mathrm{~N}$ Half-height width $(\mathrm{Hz})$} \\
& $(\mathrm{N \alpha})$ & $(\mathrm{N} \beta)$ & $(\mathrm{NK})$ & $(\mathrm{N} \alpha)$ & $(\mathrm{N} \beta)$ & $(\mathrm{N \alpha})$ \\
cyclohexane & +306.54 & +131.80 & +166.67 & 158 & 11 & 16 \\
$\mathrm{CCl}_{4}$ & +305.80 & +132.23 & +166.69 & 217 & 12 & 21 \\
$\mathrm{Et}_{2} \mathrm{O}$ & +307.25 & +131.95 & +168.79 & 114 & 9 & 16 \\
benzene & +306.19 & +131.56 & +168.12 & 159 & 11 & 20 \\
dioxane & +306.16 & +131.63 & +169.13 & 213 & 14 & 24 \\
acetone & +306.13 & +131.28 & +169.51 & 122 & 9 & 18 \\
$\mathrm{DMSO}$ & +304.77 & +131.13 & +169.69 & 291 & 16 & 30 \\
$\mathrm{CH}_{2} \mathrm{Cl}$ & +305.63 & +131.23 & +168.73 & 167 & 11 & 23 \\
$\mathrm{CHCl}_{3}$ & +305.40 & +131.40 & +167.34 & 209 & 13 & 31 \\
$\mathrm{EtOH} \mathrm{H}$ & +306.70 & +131.51 & +168.55 & 159 & 11 & 22 \\
$\mathrm{MeOH} \mathrm{H}$ & +306.73 & +131.68 & +168.88 & 135 & 10 & 20 \\
$\mathrm{H}_{2} \mathrm{O}$ & +304.82 & +131.68 & +166.18 & 279 & 16 & 32 \\
$\mathrm{CF}_{3} \mathrm{CH}_{2} \mathrm{OH}$ & +306.74 & +132.87 & +164.69 & 323 & 18 & 120 \\
\hline
\end{tabular}

Table 2

NMR measurements taken on phenyl azide in a variety of solvents at a concentration of $0.2 \mathrm{M}$ unless specified otherwise.

\begin{tabular}{ccccccc}
\hline \multirow{2}{*}{ Solvent } & \multicolumn{3}{c}{ Nitrogen shielding (ppm) } & \multicolumn{3}{c}{${ }^{14} \mathrm{~N}$ Half-height width (HZ) } \\
& $(\mathrm{N \alpha})$ & $(\mathrm{N} \beta)$ & $(\mathrm{N \kappa})$ & $(\mathrm{N} \alpha)$ & $(\mathrm{N} \beta)$ & $(\mathrm{N} \gamma)$ \\
cyclohexane & +289.16 & +137.45 & +147.60 & 441 & 16 & 76 \\
$\mathrm{CCl}_{4}$ & +287.94 & +137.60 & +147.44 & 615 & 21 & 102 \\
$\mathrm{Et}_{2} \mathrm{O}$ & +290.42 & +137.69 & +148.60 & 297 & 12 & 58 \\
benzene & +289.41 & +137.60 & +147.78 & 434 & 16 & 79 \\
dioxane & +288.41 & +137.69 & +148.46 & 733 & 26 & 125 \\
acetone & +289.62 & +137.73 & +148.37 & 356 & 14 & 68 \\
$\mathrm{DMSO}$ & +287.95 & +137.24 & +147.89 & 783 & 36 & 172 \\
$\mathrm{CH} \mathrm{Cl}_{2}$ & +288.21 & +137.12 & +147.70 & 447 & 16 & 83 \\
$\mathrm{CHCl}$ & +288.05 & +137.15 & +147.41 & 551 & 19 & 99 \\
$\mathrm{EtOH}_{3}$ & +289.80 & +137.49 & +148.04 & 451 & 17 & 78 \\
$\mathrm{MeOH}^{2} \mathrm{OH}$ & +289.76 & +137.61 & +148.24 & 369 & 15 & 66 \\
$\mathrm{H}_{2} \mathrm{O}$ & $?$ & +138.47 & +147.90 & $?$ & 32 & 168 \\
$(0.005 \mathrm{M})$ & & & & & & \\
$\mathrm{CF}_{3} \mathrm{CH}_{2} \mathrm{OH}$ & +289.42 & +138.50 & +147.44 & 796 & 28 & 157
\end{tabular}

(a) At this low concentration the broad ${ }^{14} \mathrm{NNMR}$ signal was too weak to be observed. Solution used is saturated. 
To our surprise all of the nitrogen shieldings of ethyl azide, Table 1, show no appreciable variation in solutions comprising a wide range of solvents. The solvent range includes non-polar, polar, aprotic and those which are strong donors of hydrogen bonds. The N $\alpha$ shielding range is about $2 \mathrm{ppm}$ and corresponds to a very weak deshielding as the solvent polarity increases. Solvent to solute hydrogen bonding does not appear to exert any influence on the $N \alpha$ shielding. The $N \beta$ shielding appears to be essentially immune to solvent effects a variation of less than $1 \mathrm{ppm}$ being observed for solutions in the range of solvents studied. The range for the N $\alpha$ shieldings is slightly larger, about $5 \mathrm{ppm}$, but no discernible pattern is observed with respect to the hydrogen bonding and polarity effects of the solvents used. The shielding variations for $N \alpha, N \beta$ and $N \gamma$ appear to represent the near cancellation of weak solute solvent interaction effects. Upon replacing the ethyl by a phenyl group, (Table 2), leads to a considerable change in the shieldings of the atoms of the azide group as such. However, the solvent induced ranges of nitrogen shielding variations are even smaller than those in ethyl azide. This is particularly evident for $\mathrm{N} \gamma$ which is the last sterically hindered of the three nitrogen atoms of the azide group to solvent access. Nevertheless the range of solvent induced variations for $\mathrm{N} \gamma$ in phenyl azide is as small as $0.6 \mathrm{ppm}$.

Substituent effects on the azide group nitrogen shieldings can be assessed from the data in Table 3. The compounds reported were measured in solutions of the inert solvent cyclohexane at the low concentration of $0.2 \mathrm{M}$. Thus the nitrogen shieldings of the azide group represent a rare case where substituent effects clearly exceed those of molecular interactions in solution. This situation may arise from the presence of two opposing dipoles in the covalent azide structure which could produce the cancellation of potential solute solvent interactions. The results of some INDO calculations on ethyl azide performed in the present work following a full geometry optimization show that the calculated net charges on the nitrogen atom are -0.419 for $N \alpha+0.639$ for $N \beta$ and -0.311 for $N \gamma$. Similar calculations on phenyl azide provide net charges of $-0.399,+0.631$ and -0.303 for $\mathrm{N \alpha}, \mathrm{N} \beta$ and $\mathrm{N} \gamma$ respectively.

\section{Experimental}

The compounds studied were prepared by previously published procedures for ethyl azide [4] phenyl, azide [5] n-butyl azide [6], cyclohexyl azide [6] and benzyl azide [7]. In preparing the solutions for the NMR measurements special attention was paid to the use of

Table 3

Substituent effects on the nitrogen NMR shieldings of some covalent azides in $0.2 \mathrm{M}$ cyclohexane solutions.

\begin{tabular}{|c|c|c|c|c|c|c|c|}
\hline \multirow[t]{2}{*}{$\mathbf{R}$} & \multirow[t]{2}{*}{ Solvent } & \multicolumn{3}{|c|}{ Nitrogen shielding (ppm) } & \multicolumn{3}{|c|}{${ }^{14} \mathrm{~N}$ Half-height width $(\mathrm{Hz})$} \\
\hline & & $(\mathrm{N} \alpha)$ & $(\mathrm{N} \beta)$ & $(\mathrm{N} \gamma)$ & $(\mathrm{N} \alpha)$ & $(\mathrm{N} \beta)$ & $(\mathrm{N} \gamma)$ \\
\hline n-butyl & cyclohexane & +309.65 & +131.88 & +168.54 & 229 & 13 & 31 \\
\hline cyclohexyl & cyclohexane & +297.75 & +133.42 & +166.34 & 310 & 17 & 38 \\
\hline benzyl & cyclohexane & +305.60 & +131.65 & +165.07 & 234 & 13 & 33 \\
\hline ethyl & cyclohexane & +306.54 & +131.80 & +166.67 & 158 & 11 & 16 \\
\hline phenyl & cyclohexane & +289.16 & +137.45 & +147.60 & 441 & 16 & 76 \\
\hline
\end{tabular}


pure and dry solvents. All solutions were prepared and handled under dry argon in glove bags. The nitrogen shieldings were measured on a Bruker AM 500 Spectrometer at 35 +/$0.2^{\circ} \mathrm{C}$, a V.T. unit was used to maintain the temperature. Possible random and systematic errors upon comparing the nitrogen shieldings in different solvents, were reduced to below $0.1 \mathrm{ppm}$ by taking special precautions. The shieldings were referenced externally to neat liquid nitromethane using $10 \mathrm{~mm} / 4 \mathrm{~mm}$ O.D. coaxial tubes. The inner tube contained 0.3 $M$ nitromethane in acetone- $d_{6}$ whose nitrogen shieldings is $+0.77 \mathrm{ppm}$ with respect to that of neat liquid nitromethane [1,2]. This value is obtained in the absence of bulk susceptibility effects by taking measurements with concentric spherical sample/reference containers. The content of the inner tube serves as a precise reference to the neat nitromethane standard and provides a source of deuterium lock for the NMR spectrometer. The exact resonance frequency of the ${ }^{14} \mathrm{~N}$ signal of nitromethane is $36.141524 \mathrm{MHz}$ and the corresponding frequency for a bare nitrogen nucleus is $36.136826 \mathrm{MHz}$ [1]. This value is used in conjunction with the relevant resonance frequency differences in order to calculate the nitrogen NMR shieldings with respect to that of neat nitromethane. The resonance frequencies of the samples and of the external standard were found by Lorentzian lineshape fitting of the relevant ${ }^{14} \mathrm{~N}$ signals. The shielding data given in Tables 1-3 are corrected for bulk susceptibility effects according to $\sigma \mathrm{N}($ ref. I $)=\sigma \mathrm{N}($ ref. II $)+0.77-1 / 3 \chi$ ref. II $\chi$ sample)where ref. I is neat liquid nitromethane, ref. II is a $0.3 \mathrm{M}$ solution of nitromethane in acetone- $\mathrm{d}_{6}$ and $\chi$ is the volume magnetic susceptibility in SI units. Since dilute solutions are used their susceptibilities are assumed to be equal to those of the respective solvents at $35^{\circ} \mathrm{C}$.

\section{References}

[1] M. Witanowski, L. Stefaniak, and G. A. Webb, Annual Reports on NMR Spectroscopy, Ed. G A Weth Vol. 25, Academic Press, London (1993).

[2] M. Witanowski, W. Sicinska, and G. A. Webb, Spectros. Int. J. 9 (1991) 55.

[3] M. Witanowski, J. Sitkowski, S. Biernat, B. Kamienski, B. T. Hamdi, and G. A. Webb, Magn. Reson. Chem. 23 (1983) 748.

[4] O. Dimrath and W. Wislicenus, Berichte 38 (1905) 1573.

[5] J. Ugi, H. Perlinger, and L. Beliringer, Berichte 91 (1958) 2330.

[6] E. Lieber, T. S. Chao, and C. N. R. Rao, J. Org. Chem. 22 (1957) 238.

[7] T. Curtis and G. Ehrhart, Berichte 55 (1922) 1959. 


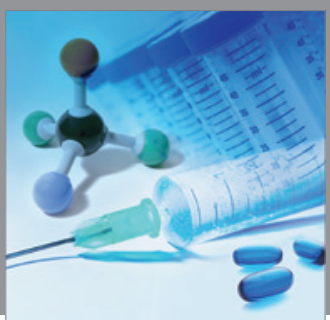

International Journal of

Medicinal Chemistry

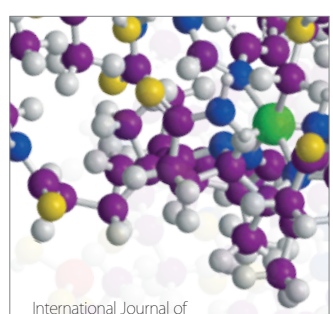

Carbohydrate Chemistry

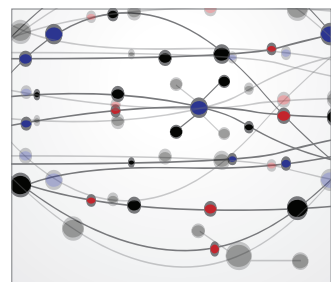

The Scientific World Journal
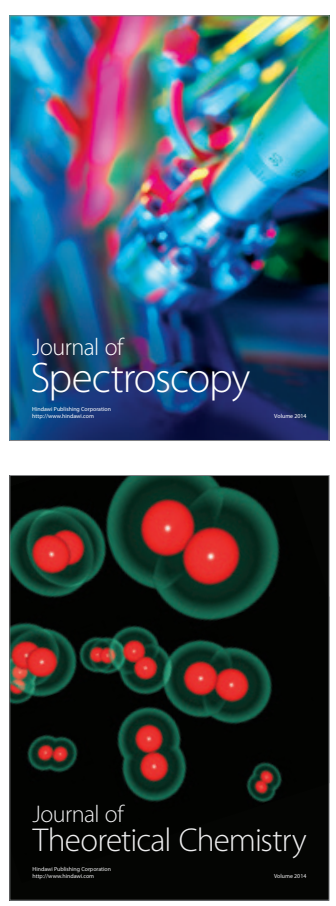
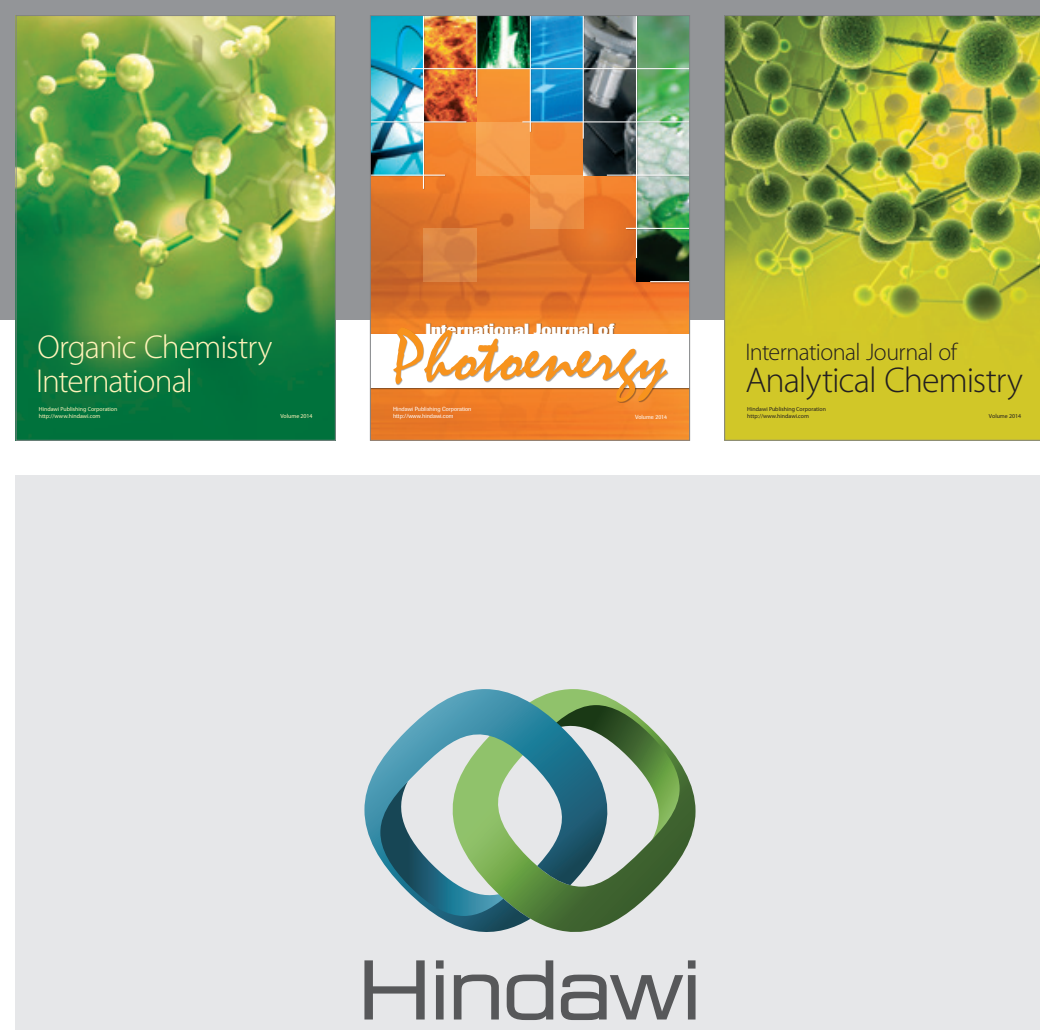

Submit your manuscripts at

http://www.hindawi.com
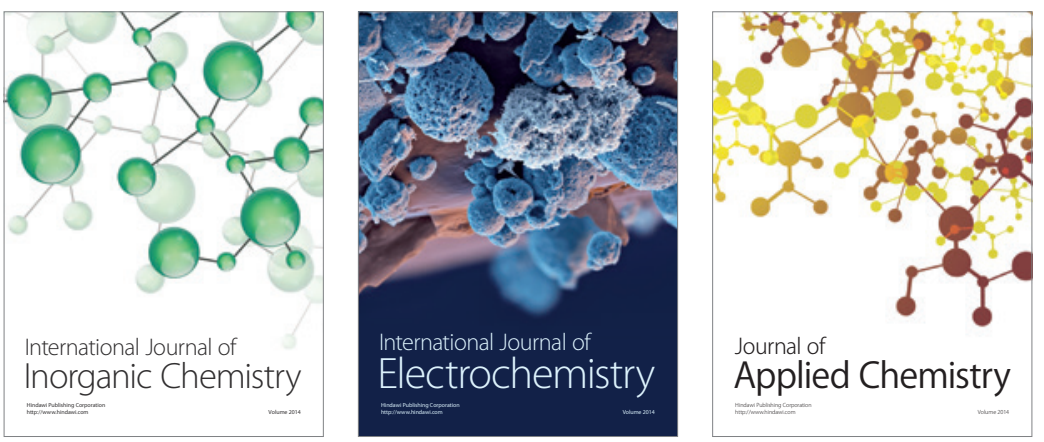

Journal of

Applied Chemistry
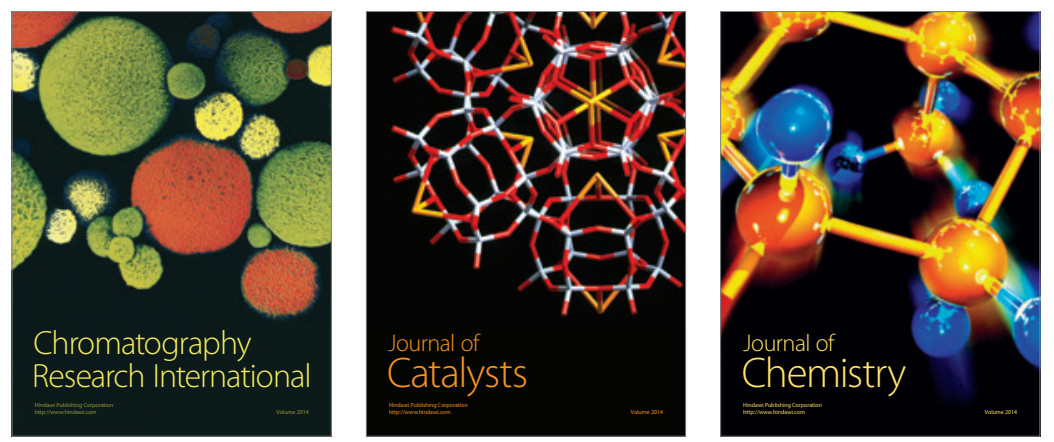
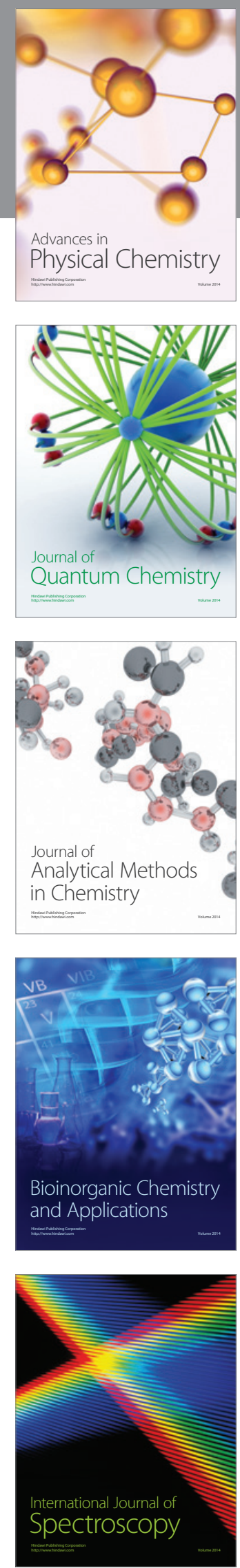